\title{
ADDITIVE MANUFACTURING FOR SUSTAINABLE CUSTOM-DESIGNED IMPLANTS
}

\author{
G.J. Booysen ${ }^{1 *}$, A.F. van der Merwe ${ }^{2} \&$ D.J. de Beer ${ }^{1}$
}

\section{ARTICLE INFO}

Article details

Presented at the $20^{\text {th }}$ annual international conference of the Rapid Product Development Association of South Africa (RAPDASA), held from 6 - 8 November 2019 in Bloemfontein, South Africa

Available online

15 Nov 2019

\section{Contact details}

* Corresponding author gbooysen@cut.ac.za

Author affiliations

1 Department of Mechanical Engineering, Central University of Technology, South Africa

2 Department of Industrial Engineering, Stellenbosch University, South Africa

\# The author was enrolled for a PhD (Industrial Engineering) degree in the Department of Industrial Engineering, Stellenbosch University, South Africa

DOI

http://dx.doi.org/10.7166/30-3-2266
ABSTRACT

Additive manufacturing (AM) has proven to be an attractive alternative manufacturing process compared with subtractive manufacturing (SM). Additive manufacturing has many advantages, such as mass customisation, less material wastage, and others listed in this article. However, the additive manufacturing of certified implants does not have the same degree of documentation and standardisation as the subtractive manufacturing process. As part of this research project, the problem statement is: "In offering additive manufacturing as an implant manufacturing solution, the complete process (design, manufacturing, and post-processing) had to be investigated in order to develop a certified manufacturing solution".

\section{OPSOMMING}

Toevoegingsvervaardiging is ' $n$ aantreklike alternatiewe vervaardigingsproses teenoor konvensionele vervaardiging. Dit bied baie voordele, soos bv. massa-aanpassing, minder materiaal vermorsing ensovoorts. Die toevoegingsvervaardiging van gesertifiseerde implantate beskik egter nie oor dieselfde mate van dokumentasie en standaardisering as die konvensionele proses nie. Die volgende probleemstelling is hier aangespreek: "Deur die aanbied van toevoegingsvervaardiging as 'n implantaat vervaardigingsoplossing, moet die volledige proses (ontwerp, vervaardiging en na-vervaardigingsverwerking) ondersoek word om 'n gesertifiseerde vervaardigingsoplossing te ontwikkel".

\section{INTRODUCTION:}

\subsection{Starting as rapid prototyping}

The genesis of additive manufacturing (AM) lies in the concept of rapid prototyping. The first 3D printing technology, stereolithography, was invented by Charles Hull in the early 1980s. It was mostly applied to the fabrication of visual prototypes to support design and marketing. As 3D technology evolved, these prototypes were used as functional prototypes that could be used in fully functional mechanical systems. Eliminating the need for tooling and fixturing results in printed prototypes being more cost-effective and taking far less time than conventionally manufactured prototypes, thus reducing the number of production development steps [1].

\subsection{Advancement from RP to AM in the biomedical field}

Vandenbroucke and Kruth [16] state that, as a result of the technical improvements of layer manufacturing (LM) processes and the possibility of processing different metals (and compounds), rapid prototyping (RP) has moved beyond its initial applications into rapid manufacturing (RM). They also point out that the progress made could benefit medical and dental applications beyond polymer applications for visual (anatomical) models or single-use surgical guides, and support the manufacturing of functional implants or prostheses. 


\subsection{Disruption of conventional sectors}

AM technology has disrupted many sectors in the medical industry as more opportunities have arisen for change and improvement and as innovations have been introduced. The process used to manufacture hearing aids demonstrates the disruption that has resulted from the introduction of $A M$ into the industry. Today, 99 per cent of hearing aids that fit into the ear are custom-made using 3D printing. As each patient's ear has a unique shape, 3D printing allows custom-shaped devices to be produced efficiently and cost-effectively [17].

The dentistry sector has transformed its manufacturing processes by embracing 3D printing; it rapidly produces crowns, bridges, plaster/stone models, and a range of orthodontic appliances such as surgical guides and aligners. Commercial 3D printing of orthodontic braces provides a good example of how 3D printing can be used efficiently and profitably to print 50000 custom-made braces daily [2].

Apart from surgical models implants and prostheses, 3D models have been used to aid the understanding of biological and biochemical structures. The use of 3D models of molecular structures, such as a polypeptide chain, has shown that students are better able to conceptualise molecular structures when such 3D models are used [17, 4]. Living human tissue has been fabricated, while personalised drug dosing and drug delivery devices with novel drug-release profiles can be created using 3D printing [17].

\subsection{Applicability of direct AM for biomedical applications}

Uklejewski, R., Winiecki, M., Rogala, P. \& Mielniczuk, J. [15] report that mass-produced orthopaedic end-osseous implants have mainly been produced from wrought or cast bar stock by five- or six-axis computerised numerical control (CNC), computer-aided design-driven (CAD) machining, or powder metallurgy production methodologies, including hot isostatic pressing and powder injection moulding of near-net-shape components. The authors maintain that the traditional process chains followed in conventional operations (mainly material removal processes) are failing due to their long lead times and material wastage - especially where complex geometries need to be created. In an article by Murr, L.E., Quinones, S.A., Gaytan, S.M., Lopez, M.I., Rodela, A., Martinez, E.Y., Hernandez, D.H., Martinez, E., Medina, F. \& Wicker, R.B. [8], the authors confirm that, through material removal processes, often 20 per cent or less of the feedstock is used. However, these traditional technologies often fail if the manufacture of an implant component involves a complex shape, including thin-walled sections where cutting operations can take a long time owing to significant material removal. The authors also maintain that, in many individual cases where patientfitted components are required, or if new constructional solutions are under development, low effectiveness and the relatively high cost of conventional (removal) machining is disadvantageous.

\subsection{Proven advanced manufacturing and biomedical applications}

In a number of reviewed articles, the authors $[3,8,16]$ all agree that the extensive development of direct digital manufacturing has recently provided new (promising) perspectives for advanced manufacturing technology, including for biomedical applications. The authors agree that recent material/compounds and process advances create both new challenges and significant opportunities for orthopaedic implant designs [7], cranioplasty implants [5], oral and maxillofacial implants, finger joint implants [3], bone substitute implants [6], customised hip and knee implants [12, 8], and dental implants [11, 16]. In the report Additive manufacturing: Opportunities and constraints [10], published by the Royal Academy of Engineering for a roundtable forum discussion held on 23 May 2013, biomedical implants were shown to be one of the key developments for the timeline 2013 to 2018, as shown in Figure 1. 


\section{AM applications timeline}

This timeline lays out past, present and potential

future AM developments and applications.

(courtesy of Graham Tromans)

\begin{tabular}{ll}
\hline $1988-1994$ & rapid prototyping \\
\hline 1994 & rapid casting \\
\hline 1995 & rapid tooling \\
\hline 2001 & AM for automotive \\
\hline 2004 & aerospace (polymers) \\
\hline 2005 & medical (polymer jigs and guides) \\
\hline 2009 & medical implants (metals) \\
\hline $2013-2016$ & aerospace (metals) \\
\hline $2013-2017$ & architecture \\
\hline $2013-2018$ & biomedical implants \\
\hline $2013-2022$ & in situ bio-manufacturing \\
\hline $2013-2032$ & full body organs \\
\hline
\end{tabular}

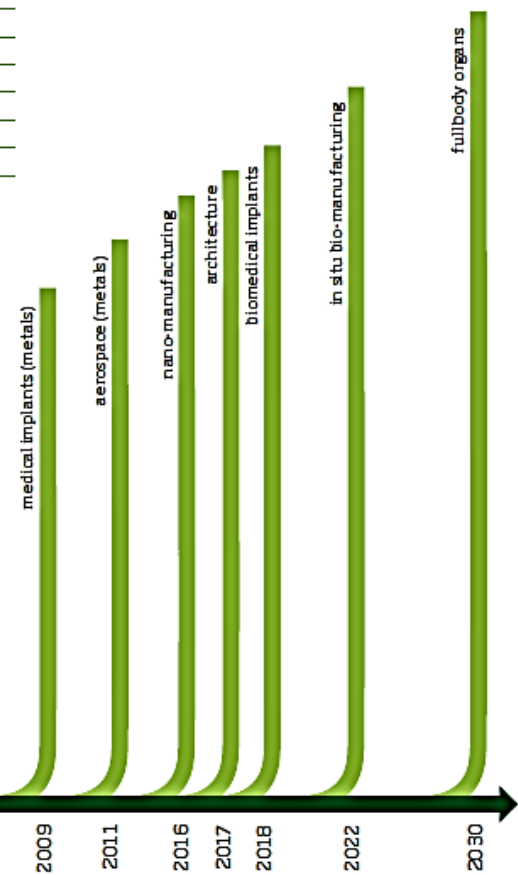

Figure 1: AM application timelines [10]

\subsection{Need to certify and standardise the SLM process}

Stahl [14] explains in the report 3D printing: Risks and opportunities that common standards need to be developed to ensure that a printed product is identical, independent of the $3 \mathrm{D}$ printer used (for the same type of technology).

The idea behind this is to ensure the same part integrity where these standards are used anywhere in the world. American Society for Testing and Materials and the International Organization for Standardization (ISO) have established technical committees for the development of standards for AM. Naguy [9], in a presentation entitled Additive manufacturing: Air Force perspective, showed the challenges faced in implementing $A M$. Concerns were raised about the lack of constrained process controls and undefined post-processing requirements, among others. The same type of certification process described by Naguy [9] is necessary for medical applications.

\subsection{Risk identification}

In the medical device industry, risk management is critical throughout the entire life cycle of a device, and it is vital to implement a risk management system successfully to ensure that a safe, effective product is manufactured on time and within budget. ISO 14971 is the harmonised standard for risk management, which defines the international requirements of risk management systems for medical devices. Using ISO 14971 and ISO 13485 as guidelines, it is important to develop a risk management procedure, including the relevant flow diagrams, to define how the AM company will do risk assessment and management. An overarching process risk assessment was done to determine the current risk index - that is, the level of risk multiplied by the probability of occurrence. As these patient-specific implants are manufactured in relatively low volumes, the probability of occurrence figures will be significantly lower than in a production environment. 
From the risk assessment it can be seen that the largest risk index relates to the design, manufacturing, and post-processing steps. The risk of infection, as part of the surgery and patient interface, is also high; but as part of this research project, the implants will be delivered non-sterile to the hospital, even though some cleaning and packaging is done. This is to shift the responsibility to the hospital, as they need to sterilise all instruments required for surgery. In order to unpack the high risks that relate to the design, manufacturing, and post-processing processes, it is important to describe and understand the process steps in each of these activities.

\section{3}

\section{DESIGN}

\subsection{Overview of design process}

In the case of medical implants, the process starts with scanning the area of the patient where the implant will be required with a computerised tomography (CT) or magnetic resonance imaging (MRI) scanner. The digital imaging and communications in medicine (DICOM) files from the scanner are converted to standard triangulation language (STL) format using dedicated software such as Mimics ${ }^{\mathrm{TM}}$ from Materialise. The software allows one to alter the grey-scale values from the DICOM images to differentiate between soft tissue and bone. In this case, the bone data are exported in STL format to show the skeletal features of the patient. The STL file is opened in $3 \mathrm{Matic}^{\mathrm{TM}}$ software - also from Materialise - from where the implant can be designed. Support structures must be added to the part to anchor it to the base on which it will be manufactured. This is done through Magics ${ }^{\mathrm{TM}}$ software. The design file is exported to RP Tools ${ }^{\mathrm{TM}}$ from EOS, where the design is sliced into virtual slices. The slice file is then exported to the direct metal laser sintering (DMLS) machine where it will be manufactured.

A layer of titanium alloy (Ti64) powder is laid down on the build platform inside the EOS M280 DMLS machine. The powder layer is the same thickness as that of the slices used in the virtual slicing of the part. The first cross-section of the part is scanned with a laser on to the powder. The laser fuses the powder particles (also referred to as selective laser melting (SLM)) in an argon atmosphere to prevent oxidation. A second layer of powder is laid down on top of the previous one, and the next cross-section is scanned. This process is repeated until the part is completed. The build platform with the parts attached is removed from the machine, stress-relieved, and the parts are separated from the base using a wire cutter. The support structures are removed from the parts, and the attachment points are ground smooth.

The design process followed for developing a patient-specific AM implant (author's own creation):

- Doctor requests a patient-specific device

- CT/MRI of patient's affected area is received

- Where necessary, the patient's impression is requested

- Check quality of scan data

- Doctor submits requirements/inputs

- Convert CT/MRI conversion with Mimics software

- Manufacture pre-operative model in nylon

- Where necessary, surgeon cuts model and prosthodontist makes a wax mock-up of proposed implant

- Wax mock-up is reverse engineered to be used as input geometry for design software

- Do initial design with 3 Matic $^{\mathrm{TM}}$ software

- Send concept to surgeon

- Do final design

- $\quad$ Analyse finite element analysis (FEA) on design

- Design cutting and drill guides

- Manufacture implant in nylon - fit on pre-operative model and use as sizer in theatre

- Do design review - design team sign-off

- $\quad$ Surgeon completes sign-off

- Manufacture implant in titanium

Figure 2 shows a generic flow diagram for all new product developments. 

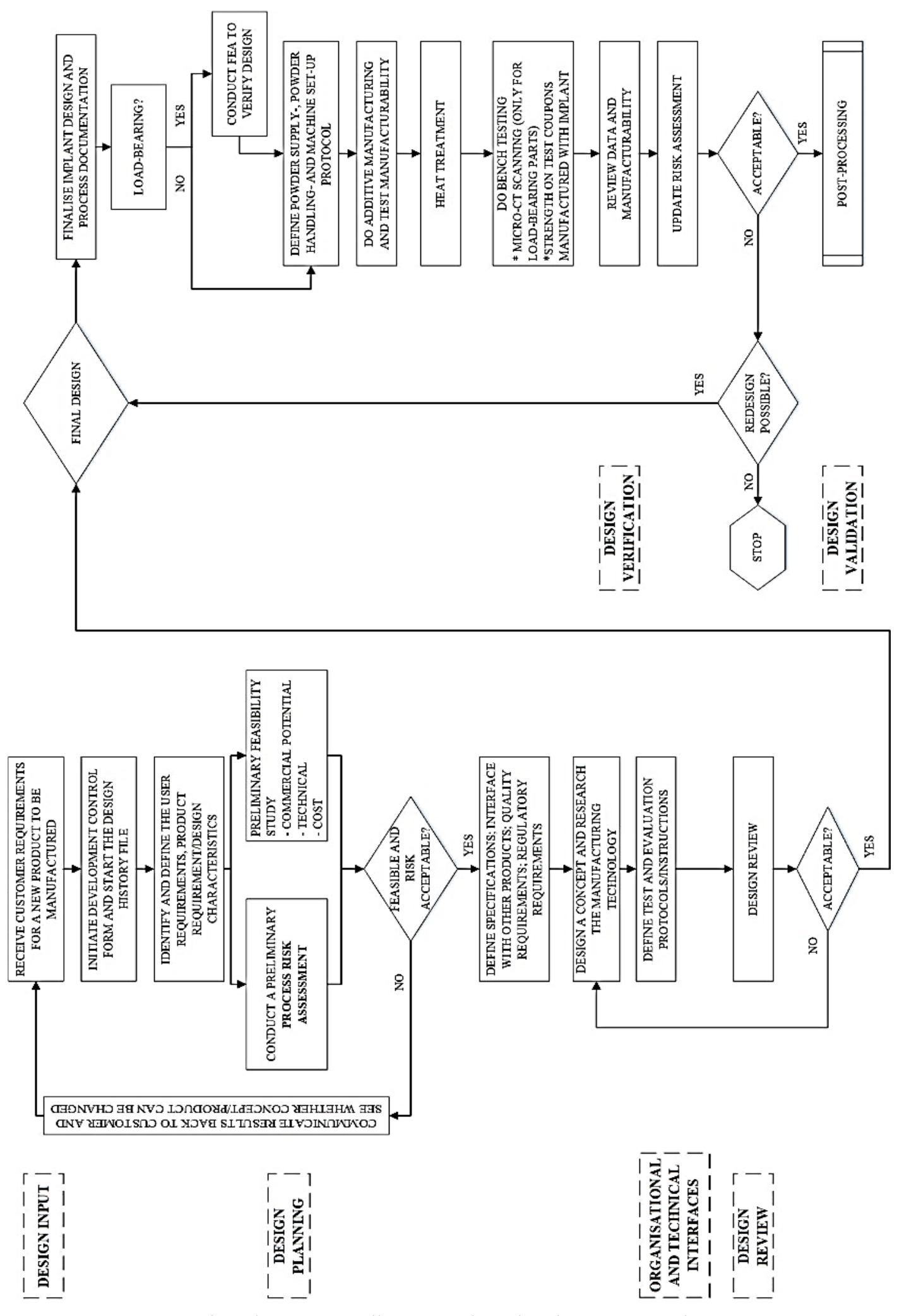

Figure 2: Generic flow diagram for all new product developments (author's own creation) 


\subsection{Current risks associated with the design process}

The risks in each process step were classified as internal (in-house) and/or external risks. This must be seen as an indication of possible risks identified (as a baseline) by the Centre for Rapid Prototyping and Manufacturing (CRPM) risk review team, which has used this implant design process and SLM process for more than 15 years (The CRPM risk review team comprises the executive management, management, the design and quality engineer, and a clinical advisor). It is not an exhaustive list, and other users of other technologies could identify additional risks. It is important to identify the current risks associated in the design process, and to develop ways to mitigate these risks. These risks will be quantified in this section. The risks are split between internal and external factors that can influence the outcome.

\subsubsection{Internal risks}

It is critical when importing the slice data into Mimics to ensure that the anterior of the scan data is the patient's anterior data, and that the scan data is not flipped when shown in the software. Inaccurate slice data to STL conversion can result in inaccurate implant designs. Another risk is that the implant is under-or over-designed; the former could result in implant failure, while the latter could mean discomfort to the patient. Lastly, it is important not to design something that cannot be additively manufactured; and here factors such as minimum wall thickness and height-to-width ratio of design features must be kept in mind. Table 1 shows some internal risks inherent in the design process, and quantifies a factor of risk to the sub-risks. The percentages shown in the tables represent the average value obtained from a questionnaire that was completed by experts in the field of $A M$. The composition of the experts was a spread between design, application, quality, and risk engineers, and $A M$ centre managers. The risk level was categorised, where one $=0$ to 24 per cent, two $=25$ to 49 per cent, three $=50$ to 74 per cent, and four $=75$ to 100 per cent.

Table 1: Identified internal risks in the design process

\begin{tabular}{|l|c|c|l|}
\hline Risks & $\%$ & Level & Possible ways to mitigate \\
\hline $\begin{array}{l}\text { Flipped import } \\
\text { CT slice data }\end{array}$ & 10 & 1 & Develop standard operating procedure (SOP) \\
\hline $\begin{array}{l}\text { Slice data to STL } \\
\text { conversion }\end{array}$ & 30 & 2 & Software validation \\
\hline $\begin{array}{l}\text { Over- or under- } \\
\text { design }\end{array}$ & 30 & 2 & $\begin{array}{l}\text { A team of engineers will conduct the formal design review, which is } \\
\text { captured in the medical device file. Finite element analysis (FEA) on } \\
\text { implant to assist design review process }\end{array}$ \\
\hline $\begin{array}{l}\text { Design not } \\
\text { suited for AM }\end{array}$ & 30 & 2 & \begin{tabular}{l} 
Develop design rules \\
\hline
\end{tabular} \\
\hline
\end{tabular}

\subsubsection{External risks}

First, the wrong patient information could be received from the radiologists, resulting in the design being based on incorrect patient anatomy. The scan quality must be checked, as slices that are too thick can result in inaccurate data extraction. For example, using this data can result in the condyle of the mandible not fitting into the glenoid fossa. Another risk is when the doctor's requirements to guide the designer in the appropriate direction are not captured accurately. A summary of some external risks is shown in Table 2 below.

Table 2: Identified external risks for the design process

\begin{tabular}{|l|c|c|l|}
\hline \multicolumn{1}{|c|}{ Risks } & $\%$ & Level & Possible ways to mitigate \\
\hline Wrong patient information & 10 & 1 & Develop medical device file \\
\hline Bad quality scan data & 40 & 2 & Develop CT scan protocol \\
\hline Incorrect input requirements from doctor & 50 & 3 & Develop medical device file \\
\hline
\end{tabular}

It is also important to check the design process against the doctor's requirements, and to structure a design review process. The design can be prototyped and checked against the pre-operative planning model, and a metrology comparison can be conducted. To minimise the risk of under- or over-designing, a FEA is proposed to check the maximum stress induced in the implant for a specific loading.

It is important to conduct a risk assessment that is linked to the development of a checklist of compliance with essential requirements for the implant, a pre-operative planning model, and drill/cutting guides. 
The risks were plotted against possible procedures, SOPs, document developments, and validation protocols. An example is shown in Table 3 of how these risks could be mitigated. The flipped import slice data risk could be addressed in both the product development procedure and the implant design SOP. The risk in the process to convert the slice data to STL file could also be addressed in the product development procedure, as well as in a full software validation. Even though the software is supplied with ISO 13485 certification, the new ISO 13485:2016 version requires the final user to validate each in-house designer. The over- and under-design risks could be mitigated as part of the product development procedure and the process overview SOP in order to be assessed as part of the design review in the medical device file.

Table 3: Example of risk mitigation process to be followed

\begin{tabular}{|c|c|c|c|c|c|c|c|c|c|}
\hline \multicolumn{10}{|c|}{ Design } \\
\hline \multirow{2}{*}{\multicolumn{2}{|c|}{$\begin{array}{l}\text { Risk } \\
\text { Classification } \\
\text { Risk } \\
\text { Description }\end{array}$}} & \multirow{4}{*}{$\begin{array}{l}\text { Internal = INT } \\
\text { External = EXT } \\
\\
\text { Product } \\
\text { Development }\end{array}$} & \multicolumn{4}{|c|}{ INT } & \multicolumn{3}{|c|}{ EXT } \\
\hline & & & $\begin{array}{c}\text { Flipped } \\
\text { Import }\end{array}$ & $\begin{array}{c}\text { Slice Data } \\
\text { to STL }\end{array}$ & $\begin{array}{l}\text { Over- } \\
\text { or }\end{array}$ & $\begin{array}{c}\text { Design } \\
\text { not }\end{array}$ & $\begin{array}{l}\text { Wrong } \\
\text { Patient }\end{array}$ & $\begin{array}{c}\text { Bad } \\
\text { Quality }\end{array}$ & $\begin{array}{l}\text { Incorrect } \\
\text { Doctor's }\end{array}$ \\
\hline \multirow{8}{*}{ } & \multirow{2}{*}{ Procedures } & & $\mathrm{x}$ & & $\mathrm{x}$ & & & & \\
\hline & & & & $\mathrm{x}$ & & & & & \\
\hline & \multirow{2}{*}{$\begin{array}{l}\text { Standard } \\
\text { Operating } \\
\text { Procedures }\end{array}$} & $\begin{array}{l}\text { Process } \\
\text { Overview }\end{array}$ & & & $\mathrm{x}$ & $\mathrm{x}$ & & $\mathrm{x}$ & \\
\hline & & Implant Design & $\mathrm{x}$ & & & & & & \\
\hline & \multirow{3}{*}{$\begin{array}{l}\text { Develop } \\
\text { Documents }\end{array}$} & $\begin{array}{l}\text { Patient CT } \\
\text { Scan Protocol }\end{array}$ & & & & & & $\mathrm{x}$ & \\
\hline & & $\begin{array}{l}\text { Medical Device } \\
\text { File }\end{array}$ & & & $\mathrm{x}$ & & $\mathrm{x}$ & & $\mathrm{x}$ \\
\hline & & Design Rules & & & & $\mathrm{x}$ & & & \\
\hline & Validation & Software & & $\mathrm{x}$ & & & & & \\
\hline
\end{tabular}

\section{CONCLUSIONS AND RECOMMENDATIONS}

The aim of this research project was to develop a certification framework focusing on Ti64 titanium powder (as the material) and SLM (as the process) for patient-specific implant manufacturing. At the start of CRPM's research into customised Ti64 implants, the surgeons had the authority to approve once-off implants. Since the creation of the South African Health Products Regulatory Authority (SAHPRA), all medical device distributors/ manufacturers have been expected to register with SAHPRA. This implies that CRPM had to develop a certification framework to continue research into applications. This was essential to develop a sustainable research and manufacturing centre adhering to the regulatory requirements.

One of the objectives was to identify key risks in the SLM process, and to develop work instructions and protocols as part of the technical certification process. These instructions will, in turn, assist in proving the repeatability and stability of the manufacturing process.

In this project, some 68 risks were identified in the following areas: design, machine setup, powder handling, SLM process, part removal, density checks, heat treatment, non-destructive testing, destructive testing, surface finishing and coating, cleaning, sterilisation, and packaging.

Of these, 41 were classified as internal risks and 27 as external risks. The purpose of this project was to develop a certification framework, and therefore it was more important to explain the methodology behind the risk identification and mitigation. 
The ISO 13485:2016 system is based on continual improvement principles, which means that, where new risks arise, the process of addressing these risks will be fast-tracked through the framework development. The action plan to mitigate these risks was to develop procedures, SOPs, supportive documents and, where needed, full machine and process validation. The procedures, SOPs, supportive documents, validations with the highest cumulative risk number, and any risk with a level of 3 to 4 were fully analysed as part of the research. Nineteen procedures were identified, and the procedure for AM was fully developed.

Thirty-four SOPs were identified in the AM manual as part of the procedure for AM. The 34 SOPs were grouped into three categories: general, EOSINT metal AM, and EOSINT polymer AM. The process overview SOP was discussed to provide an actual overview of the process chain from prosthesis request, through design and manufacturing, until medical device shipment. A proposed process chain was introduced as part of the research methodology, as shown in Figure 3 below.

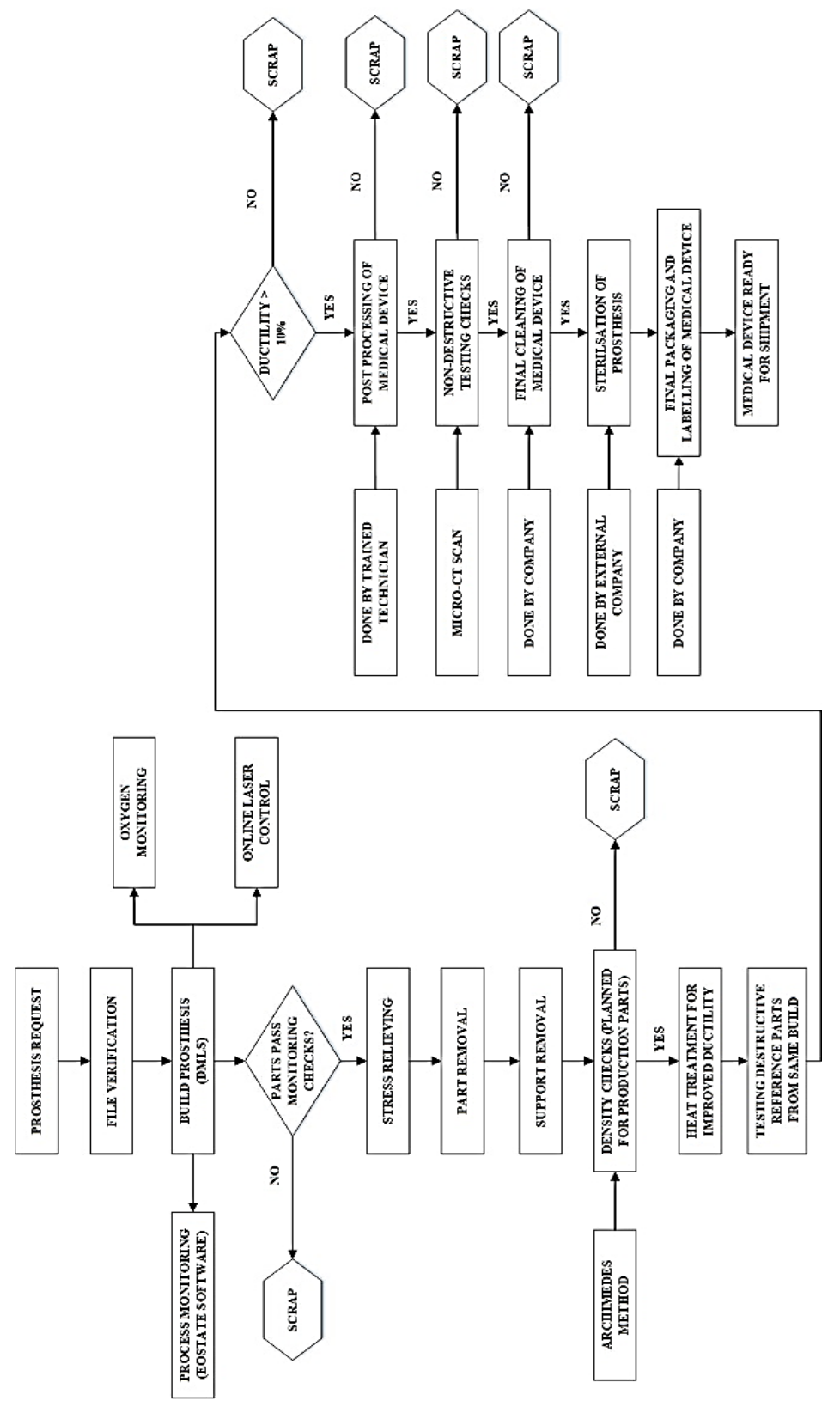

Figure 3: The flow diagrams explain the process steps of the prosthesis and prototype manufacturing as the first step in developing a procedure 
Initially, the CRPM was the only entity in Africa to develop ISO procedures for the design and manufacturing of customised implants, surgery planning models, and cutting/drilling guides or jigs manufactured by $A M$. During the past year, however, at least two more industrial companies have invested about $€ 500000$ to acquire new AM technologies, and they are currently addressing ISO certification of AM implants. It is assumed that more will follow. The complete certification process of $\mathrm{AM}$ has not been published, as a limited number of international service bureaus are working on this topic, and the in-house knowledge created is seen as intellectual property and is therefore not disclosed. Furthermore, the study could have a significant impact on the use of technology platforms at the Central University of Technology (CUT), Stellenbosch University, and the CSIR National Laser Centre, or even some local SMMEs. The study fits into the metal additive manufacturing (MAM) programme funded by the Department of Science and Technology (DST). The MAM programme forms part of a national Collaborative Programme for Additive Manufacturing (CPAM), and one of the deliverables is a fully qualified medical implant. The proposed certification framework will be a significant contributor in this MAM deliverable.

The CRPM obtained ISO 13485:2012 certification from the international regulating authority TUV (Technischer Überwachungsverein) in 2016. The scope of this certification is:

- Design, development, and production of patient-specific custom-made titanium implants using 3D printing/additive manufacturing.

- Design, development, and production of patient-specific custom-made preoperative models, jigs, and cutting guides in nylon using 3D printing/additive manufacturing.

- $\quad$ Contract production of titanium implants using 3D printing/additive manufacturing.

- Contract production of preoperative models, jigs, and cutting guides in nylon using 3D printing/additive manufacturing.

The CRPM was successful in migrating to the revised ISO 13485 (2016 version), and the external audit was completed by TUV SUD from 22 to 23 March 2018. The International Organization for Standardization (ISO) revised the 2012 version, and the ISO 13485:2016 was designed to respond to the latest quality management system practices, including changes in expectations. TUV SUD also audited all the patient files, as the CRPM had assisted more than 25 patients in the past two years. Some of the implants designed and manufactured by CRPM are shown in Table 4. No patient's identity is revealed in the images below.

Table 4: AM implants designed and manufactured by CRPM (see online version for colour)

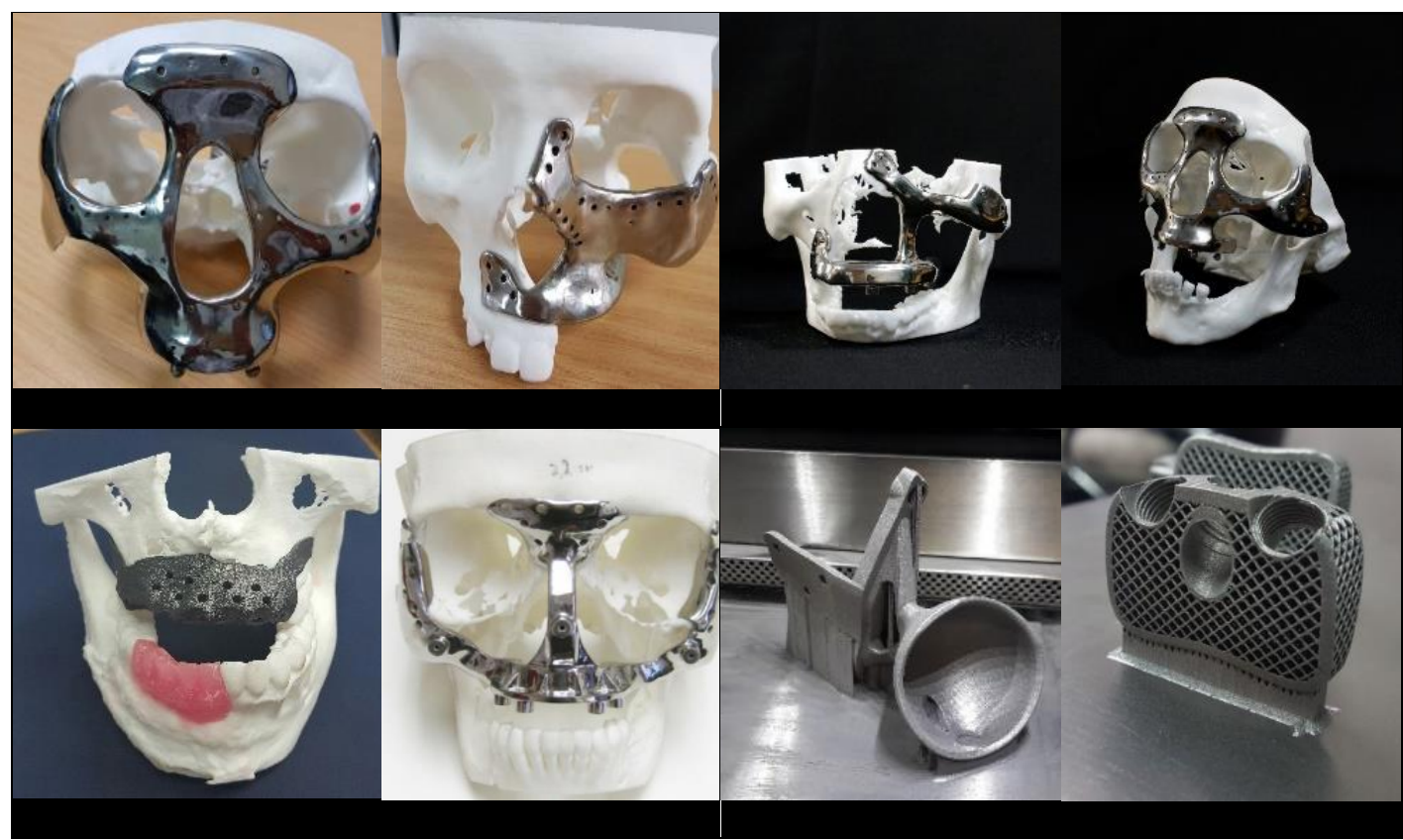




\section{Recommendations and future work}

The aim of this research project was to develop a certification framework for additive manufactured patient-specific implant manufacturing, and to develop similar documentation and standardisation as available with the subtractive manufacturing process. The recommendations and future work suggested below will assist in fast-tracking this certification process.

Software: Online planning software can be used to discuss a patient's case remotely with the surgeon, as the data or object can be virtually rotated to indicate which area needs to be removed; these parameters can then be locked as design input on the medical device file. This online communicating tool can provide faster feedback from surgeons on design concepts.

Mobile app for surgeons:

- $\quad$ Post-operative reviews, where the surgeon can give feedback after an operation on possible improvements.

- Meeting minutes translated from voice note to text, and logged into the quality management system (QMS).

Software is currently being developed to track powder batch numbers as batches are mixed to form recycled powder; this will be an essential input to powder-aging analysis.

Statistical shape modelling techniques can be used to generate swifter patient-specific geometry from a database - for example, mandible shapes and sizes.

Hardware: Process monitoring can be further expanded to accommodate recoating monitoring (scanning every layer) and melt pool monitoring. Software must be developed to translate all this data into a 3D rendering to outline possible areas of concern. Only these areas then need to be scanned using CT scanning, and not the complete part, which will result in process cost savings.

Hardware is currently being developed to monitor powder storage, especially with reactive materials such as titanium. Monitoring of oxygen content, temperature, and relative humidity are taken in real-time.

An automatic surface finishing system must be acquired, as hand-polishing techniques are currently used. It is important to note that titanium is not the easiest material to polish, and that sharp edges and fine features must be preserved.

Quality Management System:

The systems currently being used are both a manual and an automated system, where files are linked to each other and due dates are flagged on procedures and SOPs review dates. The audit planning schedules and responsible persons can easily be assigned. It would be advantageous if such an automated system could link to an enterprise resource planning (ERP) system to assist with resource allocation and product traceability.

\section{ACKNOWLEDGEMENTS}

This research was supported and funded by the South African Department of Science and Technology through the Collaborative Program in Additive Manufacturing, Contract No.: CSIR-NLC-CPAM-15MOA-CUT-01.

The support of the South African Research Chairs Initiative of the Department of Science and Technology and National Research Foundation of South Africa (Grant No.: 97994) is acknowledged.

The financial support of the Carl and Emily Fuchs Foundation for the reconstructive surgery cases is gratefully acknowledged. 


\section{REFERENCES}

[1] Conner, B.P.,Manogharan, G.P., Martof, A.N., Rodomsky, L.M., Rodomsky, C.M., Jordan, D.C. \& Limperos, J.W. 2014. Making sense of 3-D printing: Creating a map of additive manufacturing products and services. Additive Manufacturing, 1(4), pp. 64-76.

[2] Dodziuk, H. 2016. Applications of 3D printing in healthcare. Kardiochirurgia, I Torachirurgia Polska, 13(3), pp. 283-293.

[3] Gibson, I., Cheung, L.K., Chow, S.P., Cheung, W.L., Beh, S.L., Savalani, M. \& Lee, S.H. 2006. The use of rapid prototyping to assist medical applications. Rapid Prototyping Journal, 12, pp. 53-58.

[4] Gross, B.C., Meisel, J.E., Lockwood, S.Y. \& Chen, C. 2014. Evaluation of 3D printing and its potential impact on biotechnology and the chemical sciences. Anal. Chem, 86(7), pp. 3240-3253.

[5] Hieu, L.C., Zlatov, N., Vander Sloten, J., Bohez, E., Khanh, L., Binh, P.H., Oris, P. \& Toshev, Y. 2005. Medical rapid prototyping applications and methods. Assembly Automation, 25, pp. 284-292.

[6] Hoeges, S., Lindner, M., Fischer, H., Meiners, W. \& Wissenbach, K. 2009. Manufacturing of bone substitute implants using selective laser melting. In: VanderSloten, J., Verdonck, P., Nyssen, M. \& Haueisen, J. (eds) $4^{\text {th }}$ European Conference of the International Federation for Medical and Biological Engineering. IFMBE Proceedings, 22, Berlin: Springer.

[7] Hollander, D.A., Wirtz, T., Von Walter, M., Linker, R., Schultheis, A. \& Paar, O. 2003. Development of individual three-dimensional bone substitutes using SLM. European Journal of Trauma, 4, pp. $228-234$.

[8] Murr, L.E., Quinones, S.A., Gaytan, S.M., Lopez, M.I., Rodela, A., Martinez, E.Y., Hernandez, D.H., Martinez, E., Medina, F. \& Wicker, R.B. 2009. Microstructure and mechanical behavior of Ti6Al4V produced by rapid-layer manufacturing, for bio-medical applications. Journal of Mechanical Behavior Biomedical Materials, 2, pp. 20-32.

[9] Naguy, T. 2014. Additive manufacturing opportunities within DoD maintenance. [Electronic] Available: https: / / www.sae.org/events/dod/presentations/2014/11-

19/additive_manufacturing_opportunities_within_dod_maintenance.pdf [Accessed June 30, 2016 ].

[10] Royal Academy of Engineering. 2013. Additive Manufacturing: Opportunities and Constraints. A summary of a roundtable forum discussion. [Online] Available: https://www.raeng.org.uk/publications/reports/additive-manufacturing [Accessed August 13, 2017], pp. 7.

[11] Santos, E.C., Shiomi, M., Osakada, K. \& Laoui, T. 2006. Rapid prototyping of metal components by laser forming. International Journal of Machine and Tools Manufacture, 46, pp. 1459-68.

[12] Sercombe, T., Jones, N., Day, R. \& Kop, A. 2008. Heat treatment of Ti-6Al-7Nb components produced by selective laser melting. Rapid Prototyping Journal, 14, pp. 300-304.

[13] Singare, S., Yaxiong, L., Dichen, L., Bingheng, L., Sanhu, H. \& Gang, L. 2006. Fabrication of customized maxillofacial prosthesis using computer-aided design and rapid prototyping techniques. Rapid Prototyping Journal, 12, pp. 206-213.

[14] Stahl, H. 2013. 3D printing: Risks and opportunities report. Öko-Institut e.V. [Electronic]. Available: https: / /www.oeko.de/oekodoc/1888/2013-532-en.pdf [Accessed March 13, 2018].

[15] Uklejewski, R., Winiecki, M., Rogala, P. \& Mielniczuk, J. 2011. Selective laser melted prototype of original minimally invasive resurfacing hip endoprosthesis. Rapid Prototyping Journal, 17(1), pp. 76-85.

[16] Vandenbroucke, B. \& Kruth, J-P. 2007. Selective laser melting of biocompatible metals for rapid manufacturing of medical parts. Rapid Prototyping Journal, 13(4), pp. 196-203.

[17] Ventola, C.L. 2014. Evaluation of 3D printing and its potential impact on biotechnology and the chemical sciences. Anal. Chem., 86(7), pp. 3240-3253. 